\title{
COMPARISON OF EFFICACY OF INJECTABLE STEROIDS VERSUS CONSERVATIVE MANAGEMENT FOR DE QUERVAINS'S TENOSYNOVITIS
}

\author{
Nasim Ilyasa, Fouzia Hanifb, Rajesh Kumar Panjwanic, Sheikh Kashif Rahimd, Asma Abdul Qadeere, \\ Abdul Hameed \\ ${ }^{a}$ Associate Professor, Department of Biochemistry, Poonch Medical College, Azad Jammu Kashmir. \\ ${ }^{b}$ Assistant Professor, Department of Biochemistry Federal Medical \& Dental Medical College, Islamabad. \\ 'Deputy Director, Sindh Healthcare Commission. \\ ${ }^{\mathrm{d} A s s o c i a t e}$ Professor, Department of Community Medicine, Rawal Institute of Health Sciences, \\ Islamabad. \\ eAssistant Professor, Department of Community Medicine, Rawal Institute of Health Sciences, \\ Islamabad.

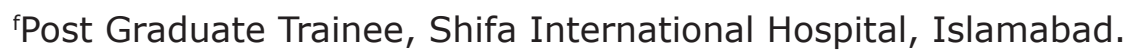

\section{ABSTRACT:}

BACKGROUND \& OBJECTIVE: De Quervain's tenosynovitis is tenosynovitis of the abductor pollicis longus and extensor pollicis brevis tendons, occurs due to chronic overuse of the wrist and hand. To compare effectiveness of steroid injection with conservative management of De Quervains's tenosynovitis.

METHODOLOGY: Randomized prospective study was conducted at the various private orthopedic clinic across Rawalpindi district, along with collaboration of community medicine department, Rawal Institute of health sciences, Islamabad. The study population was divided into two groups, i.e., group-A and group-B. Group-A was given inj. corticosteroid and group B was given conservative management. The severity of pain (Visual analogue scale) and Finkelstein test were recorded on baseline and after 3 weeks follow up.

RESULTS: Our study included 96 diagnosed cases of de Quervains tenosynovitis on a positive Finkelstein test; 48 were given corticosteroid injection and 48 were conservatively treated. The mean age in corticosteroid's injection group was $34.76+6.95$ years whereas the mean age in conservative management group was 31.7+8.91 years. Post-intervention 13, 29 patients had a positive Finkelstein test in corticosteroid and conservative groups respectively. Although the difference in pre intervention pain score between the two groups was not statistically significant but significantly lesser pain scores in the corticosteroid group; $(p=0.00)$.

CONCLUSION: Steroid injection produced better results in terms of relief in pain and negative Finkelstein test as compared to conservative treatment.

KEYWORDS: Injectable steroids, Tenosynovitis, Conservative management.

\section{How to cite this:}

https://doi.org/10.37723/jumdc.v12i3.555

Ilyas N, Hanif F, Panjwani RK, Rahim SK, Qadeer AA, Hameed A. Comparison of efficacy of injectable steroids versus conservative management for De Quervains's tenosynovitis. Journal of University Medical \& Dental College. 2021;12(3):217-221.https://doi.org/10.37723/jumdc.v12i3.555

This is an Open Access article distributed under the terms of the Creative Commons Attribution License (http://creativecommons.org/licenses/by/4.0), which permits unrestricted use, distribution, and reproduction in any medium provided the original work is properly cited. 


\section{INTRODUCTION:}

De Quervain's tenosynovitis (DQT) is also known as De Quervain's tendinosis, tendonitis, disease, or syndrome caused by impaired gliding of the tendons of the abductor pollicis longus ( $A P L)$ and extensor pollicis brevis (EPB) muscles ${ }^{[1]}$.These musculotendinous units control the position and orientation, force application and joint stability of the thumb. The impaired gliding is believed to be as a result of thickening of the extensor retinaculum at the first dorsal (extensor) compartment of the wrist, with subsequent narrowing at the fibro-osseous canal ${ }^{[2]}$.

Harry Finkelstein, an American surgeon (18651939), described the Finkelstein's test or Finkelstein's sign in 1930. It is a provocative test for diagnosis of De Quervain's disease that can easily be performed in an office setting or at the bedside ${ }^{[3]}$. Finkelstein's test produces severe tenderness and usually pain on the radial aspect of the wrist when the thumb is flexed into the palm and the wrist is ulnar deviated. Workers who perform repetitive activities of the wrist and hand and those who routinely use their thumbs in grasping and pinching motions in a repetitive manner are most susceptible to $\mathrm{DQT}^{[4]}$.

In a community based study done in UK, the prevalence of DQT was $0.5 \%$ in men and $1.3 \%$ in women. In a study done in Japan it was reported that corticosteroids injection was efficacious in $90 \%$ of the study population ${ }^{[5]}$. A local study done in DHQ Hospital Battagram, showed higher prevalence of DQT among females with 9:1 ratio as compared to males. The authors concluded that surgical treatment was excellent with $96 \%$ patients completely relieved of symptoms ${ }^{[6]}$. Keeping in mind the importance of hand use in our daily life and ailment of DQT, its associated effects, we planned to address this issue in our local setting as there is no previous research on this topic from our settings ${ }^{[7]}$. At current, both operative and non-operative, management of DQT is done ${ }^{[8]}$. However, no first line or priority method is followed. This study will thus help in streaming the first line appropriate treatment modality for this ailment. To compare the efficacy of steroid injection with conservative management in the treatment of DQT.

Keeping in mind the importance of hand use in our daily life and ailment of DQT, its associated effects, we planned to address this issue in our local setting as there is no previous research on this topic from our settings ${ }^{[7]}$. At current, both operative and non-operative, management of DQT is done ${ }^{[8]}$. However, no first line or priority method is followed. This study will thus help in streaming the first line appropriate treatment modality for this ailment. To compare the efficacy of steroid injection with conservative management in the treatment of DQT.

Corresponding Author:

Dr. Nasim Ilyas

Associate Professor, Department of Biochemistry, Poonch Medical College, AJK Email:biochemistry.iimct@gmail.com

\section{METHODOLOGY:}

Randomized prospective study, (Line listing was done, patients with even, odd number serial numbers were selected among group A and B respectively) was done at private orthopedic clinics across Rawalpindi district, in collaboration with community medicine department, RIHS, Islamabad. Prior to the start of study approval from departmental ethical committee was obtained. Only those patients were selected which had wrist pain and positive Finkelstein's test. Those patients having chronic bone disease such as rheumatoid arthritis were excluded from the study. Total duration of study was 15 months, starting from 1st July 2017 to 31th December 2018.

Group-A Patients were given one local injection with $10 \mathrm{mg}(1 \mathrm{ml})$ triamcinolone acetonide. In case of group-B conservative management, treatment included splinting, non-steroidal antiinflammatory drugs like (ibuprofen) and rest ${ }^{[9]}$. The severity of pain (Visual analogue scale) and Finkelstein test were recorded on baseline and after 3 weeks follow up. The data was collected from private orthopedic clinics across Rawalpindi district and analyzed by using SPSS V.19 at community medicine department, RIHS, Islamabad. Chi-square test and paired t-test was used. 


\section{RESULTS:}

Our study included 96 patients 17 (16.3\%) males and 79 (75.8\%) females), 48 in the corticosteroid group and 48 in the conservative group. The age of the patients ranged 20 to 52 years with a mean age of $34.413 \pm 7.08$ years. The mean age in corticosteroid's injection group was $34.76 \pm 6.95$ years whereas the mean age in conservative management group was $31.7 \pm 8.91$ years. The involvement of the right hand was 72 (75\%) and remaining 15 (25\%) had involvement of the left hand.

Post-intervention 13 and 29 patients had a positive Finkelstein test in corticosteroid and conservative groups respectively. Pre intervention pain score in the corticosteroids group ranged from 7-10 with a mean of $8.23 \pm 1.040$. Pre intervention pain score in the conservative group ranged from $6-10$ with a mean of $8.00+1.462$ $(p<0.001)$

Post-intervention pain score in the corticosteroids group ranged from 0-6 with a mean of $1.93 \pm 2.116$. Post- intervention pain score in the conservative group ranged from $0-8$ with a mean of $4.67 \pm 2.202$. Hence the two groups were significantly different after the treatment with significantly lesser pain scores in the corticosteroid group; $(p<0.001)$.

Table-I: Comparing the Post-Intervention Finkelstein Test

\begin{tabular}{|c|c|c|c|c|}
\hline \multirow{2}{*}{ Group } & \multirow{2}{*}{ N } & \multicolumn{2}{|c|}{ Post intervention Finkelstein test } & \multirow{2}{*}{ p-value } \\
\cline { 3 - 4 } & & Positive & Negative & \\
\hline Corticosteroid Injection & 48 & $13(27.1)$ & $35(72.9)$ & $<0.001$ \\
\hline Conservative Management & 48 & $29(60.4)$ & $19(39.6)$ & \\
\hline
\end{tabular}

Table -II : Cortico-SteroidGroup ; Pre And Post Intervention Pain Score

\begin{tabular}{|c|c|c|c|c|}
\hline Pain Score & N & Mean & Std. Deviation & p-value \\
\hline Pre intervention & 48 & 8.23 & 1.040 & $<0.001$ \\
\hline Post intervention & 48 & 1.93 & 2.116 & \\
\hline
\end{tabular}

\section{DISCUSSION:}

De Quervain's tenosynovitis is Inflammation of tendons on the side of the wrist at the base of the thumb. Patients report pain at the dorsolateral aspect of the wrist, with referral of pain toward the thumb and/or the lateral forearm ${ }^{[10]}$. De Quervain, a Swiss physician, is given credit for first describing this condition with a report of five cases in 1895 and eight additional cases in 1912 $[2,4,10]$.

De-Quervain's disease commonly managed by alteration of wrist activities, analgesic drugs, corticosteroids injection, bracing and casting ${ }^{[11]}$. Some authors promote full-time cast application for four to six weeks, believing that tendonitis resolution with rest. Significant improvement also could be anticipated when steroid injection is used to treat this disease, ${ }^{[12]}$ but patients have a fear of steroid side effects (osteomyelitis, necrotizing fasciitis; cellulitis, tendon ruptures, hypopigmentation or as skin defect). Surgery is reserved only for those with intense chronic pain unresponsive to conservative treatment [13].

There are several studies which had shown promising effects local corticosteroid injection. In a study by Jirarattana. The success rate with steroid injection was $67 \%{ }^{[14]}$. Avci et al claimed $100 \%$ success rate, while Takuya Sawaizumi, claimed $94 \%$ success rate in their study in which they locally injected Triamcinolone for patients with De Quervain \'s disease ${ }^{[15,16]}$. These results were similar to the results of our study where $80 \%$ patients had a negative Finkelstein test after steroid injection. This study was different from our study in the way that we used triamcinolone acetonide for injection as compared to methyl prednisolone ${ }^{[16]}$. However even using a different chemical steroid did not affect the outcome much. 
Another study reported use of removable thumb holder and wrist splint can provide pain relief in patients who fear injection [17]. Previous metaanalysis showed $83 \%, 17 \%$ cure rate with injection and splint respectively ${ }^{[18]}$. The efficacy rate was $89 \%$, with two-point injection as compared to one-point injection. Recurrence rate was $10 \%$ and $1 \%$ rate ${ }^{[19]}$. Barlett $\mathrm{NL}$ reported $94 \%$ success rate of intra-sheath injections of Triamcinolone ${ }^{[20]}$. The success rate were higher than that of our results, this may be due to difference in the injection techniques and also because of use of lidocaine.

A European study compared short- and long-term effects of corticosteroid and placebo, showed that steroids were effective in both short and long term ${ }^{[21]}$. Another study reported use of NSAIDs in addition to steroid injection, showed cure rate of $100 \%, 76 \%$ in mild groups and severe group respectively ${ }^{[22]}$. We had not compared the results between mild, moderate and severe pain groups as was done in this study.

A study conducted in Iran comparative trail on casting and steroids with casting, had shown similar result to our study. They included 73 patients 37 in steroid group efficacy was observed to be $85.6 \%{ }^{[23]}$. They also excluded any patient with pregnancy just as we did. The main reason of excluding pregnant ladies was that the symptoms in pregnant women may resolve spontaneously either at the end of pregnancy or at the end of breast feeding ${ }^{[23]}$. There will need further studies and larger sample size with follow up mechanism to establish these associations with effectiveness.

\section{CONCLUSION:}

Steroid injection is more efficacious for de Quervain's tenosynovitis in terms of relief in pain and negative Finkelstein test as compared with conservative treatment.

ACKNOWLEDGEMENT: We offer over sincere thanks to administration of RIHS.

CONFLICT OF INTEREST: None. GRANT SUPPORT \& FINANCIAL DISCLOSURE: None.

\section{REFERENCES:}

1. Gross GA, George JW. Orthopedic injury in pregnancy. Clinical Obstetrics and Gynecology. 2016;59(3):629-638. Doi: $10.1097 /$ GRF.0000000000000221

2. Lee ZH, Stranix JT, Anzai L, Sharma S. Surgical anatomy of the first extensor compartment: A systematic review and comparison of normal cadavers vs. De Quervain syndrome patients. Journal of Plastic, Reconstructive \& Aesthetic Surgery. 2017; 70(1):127-131. Doi: 10.1016/j.bjps.2016.08.020.

3. SatoJ, Ishii Y, Noguchi H. Clinical and ultrasound features in patients with intersection syndrome or De Quervain's disease. Journal of Hand Surger. 2016; 41(2):220-225. Doi: $10.1177 / 1753193415614267$.

4. Wagner ER, Gottschalk MB. Tendino-pathies of the forearm, wrist and hand. Journal Clinics in Plastic Surgery. 2019; 46(3):317327. Doi: $10.1016 /$ j.cps.2019.02.005.

5. Som A, Wermuth HR, Singh P. Finkelstein Sign. [Updated 2020 Dec 23]. In: StatPearls [Internet]. Treasure Island (FL): StatPearls Publishing; 2021 Jan-. Available from: https://www.ncbi.nlm.nih.gov/books/ NBK539768/

6. Zarin M, Ahmad I. Surgical treatment of de Quervain's disease. Journal of the College of Physicians and Surgeons Pakistan: JCPSP. 2003;13(3):157-158. Doi: 03.2003/ jcpsp. 157158

7. Kuo YL, Hsu CC, Kuo LC, Wu PT, Shao CJ, $\mathrm{Wu} \mathrm{KC}$, et al. Inflammation is present in De Quervain's disease-Correlation study between biochemical and histopathological evaluation. Annals of Plastic Surgery. 2015; 74 (2): S146-151.

8. Cavaleri R, Schabrun SM, Te M, Chipchase LS. Hand therapy versus corticosteroid injections in the treatment of De Quervain's disease: A systematic review and meta-analysis. Journal of Hand Therapy 2016; 29(1):3-11. Doi: $10.1016 /$ j.jht.2015.10.004.

9. Ippolito JA, Hauser S, Patel J, Vosbikian M, Ahmed I. Nonsurgical treatment of DeQuervain tenosynovitis: A prospective randomized trial. Hand (NY) 2018;1558944718791187. Doi: $10.1177 / 1558944718791187$. 
10. Satteson E, Tannan SC. De Quervain Tenosynovitis. [Updated 2020 Nov 1]. In: StatPearls [Internet]. Treasure Island (FL): StatPearls Publishing; 2020 Jan-. Available from: https://www.ncbi.nlm.nih.gov/books/ NBK442005/

11. Huisstede BM, Gladdines S, Randsdorp MS, Koes BW. Effectiveness of conservative, surgical and postsurgical interventions for trigger finger, Dupuytren disease and De Quervain disease: A systematic review. Archives of Physical Medicine and Rehabilitation.2018; 99(8):1635-1649.e21. Doi: 10.1016/j.apmr.2017.07.014.

12. Pooswamy SS, Muralidharaogpalan NR. Intra sheath corticosteroid injection for De Quervain's tenosynovitis. International Journal of Research in Orthopaedics. 2019; 5:403-407.

13. Goel R, Abzug JM. De Quervain's tenosynovitis - A review of the rehabilitative options. Hand. $2015 ; 10(1): 1-5$.

14. Jirarattanaphochai K, Saengnipanthkul S, Vipulakorn K, Jianmongkol S, Chatuparisute $P$, Jung S. Treatment of de Quervain disease with triamcinolone injection with or without nimesulide. A randomized, double-blind, placebo-controlled trial. Journal of Bone \& Joint Surgery. 2004; 86(12):2700-2706. Doi: 10.2106/00004623-200412000-00017.

15. Avci S, Yilmaz C, Sayli U. Comparison of nonsurgical treatment measures for de Quervain's disease of pregnancy and lactation. The Journal of hand surgery. 2002; 27:322-324.

16. Sawaizumi $T$, Nanno $M$, Ito $H$. Intrasheath Triamcinolone Injection for the Treatment of Trigger Digits in Adult. Hand Surgery 2005; 10(1): 37-42.

17. Mallick SK, Jha DK, Majumdar A, Mahapatra S. A comparative study between splinting versus corticosteroid injection in dequervain's disease. International Journal of Orthopaedics Sciences. 2018; 4(3): 22-26

18. Muhammad RS, Amjad T, Zulfqar A, Ali N. Comparison of pain relief among patient of De Quervain disease with steroid injection versus surgical decompression. Journal of Shaikh Zayed Medical College. 2012; 3:301304.
19. Oh JK, Messing S, Hyrien O, Hammert WC. Effectiveness of corticosteroid injections for treatment of De Quervain's tenosynovitis. Hand (N Y)2017; 12:357-361.

20. Bartlett NL, Wilson WH, Leonard JP. Reply to T.M. Weis et al. Journal of Clinical Oncology: official Journal of the American Society of Clinical Oncology. 2019;37(31):2953. Doi: 10.1200/JCO.19.01617.

21. Raza W, Bakar A, Awan S, Qadir RI. Outcome of Steroid Injections in Patients with DeQuervain's Tenosynovitis. Journal Medical Sciences. 2020;28(2):162-166.

22. Peters C, Winters JC, Groenier KH. Randomised controlled trial of local corticosteroid injections for de Quervain's tenosynovitis in general practice. Biomed Central. 2009; 10:131.

23. Mehdinasab SA, Alemohammad SA. Methylprednisolone acetate injection plus casting versus casting alone for the treatment of de quervain's tenosynovitis. Journal of Iranian Medicine. 2010; 4:270-274.

\section{Author's Contribution:}

Nasim Ilyas: Proposed topics, basic study design, data collection and statical analysis.

Fouzia Hanif: Interpretation of results, literature review, intellectual content.

Rajesh Kumar Panjwani: Analysis of data, study design, methodology, and proofreading.

Sheikh Kashif Rahim: Analysis of data, study design and methodology.

Asma Abdul Qadeer: Interpretation of data for the work.

Abdul Hameed: Acquisition and drafting of the work.

Submitted for Publication: 12-01-2021 Accepted After revision: 15-06-2021 